\title{
Seasonal, Diurnal, and Solar-Cycle Variations of Electron Density at Two West Africa Equatorial Ionization Anomaly Stations
}

\author{
Frédéric Ouattara, ${ }^{1}$ Doua Allain Gnabahou, ${ }^{2}$ and Christine Amory Mazaudier ${ }^{3}$ \\ ${ }^{1}$ Ecole Normale Supérieure de l'Université de Koudougou, P.O. Box 376, Koudougou, Burkina Faso \\ ${ }^{2}$ Lycée Provincial de Koudougou, Direction Régional du Centre Ouest, P.O. Box 39, Koudougou, Burkina Faso \\ ${ }^{3}$ LPP-UPMC, CNRS, 4 Avenue de Neptune, 94107 Saint Maur des Fossés, Paris, France
}

Correspondence should be addressed to Frédéric Ouattara, fojals@yahoo.fr

Received 1 December 2011; Revised 31 January 2012; Accepted 23 February 2012

Academic Editor: Yuichi Otsuka

Copyright (c) 2012 Frédéric Ouattara et al. This is an open access article distributed under the Creative Commons Attribution License, which permits unrestricted use, distribution, and reproduction in any medium, provided the original work is properly cited.

We analyse the variability of foF2 at two West Africa equatorial ionization anomaly stations (Ouagadougou and Dakar) during three solar cycles (from cycle 20 to cycle 22), that is, from 1966 to 1998 for Ouagadougou and from 1971 to 1997 for Dakar. We examine the effect of the changing levels of solar extreme ultraviolet radiation with sunspot number. The study shows high correlation between foF 2 and sunspot number (Rz). The correlation coefficient decreases from cycle 20 to cycle 21 at both stations. From cycle 21 to cycle 22 it decreases at Ouagadougou station and increases at Dakar station. The best correlation coefficient, 0.990 , is obtained for Dakar station during solar cycle 22. The seasonal variation displays equinoctial peaks that are asymmetric between March and September. The percentage deviations of monthly average data from one solar cycle to another display variability with respect to solar cycle phase and show solar ultraviolet radiation variability with solar cycle phase. The diurnal variation shows a noon bite out with a predominant late-afternoon peak except during the maximum phase of the solar cycle. The diurnal Ouagadougou station foF2 data do not show a significant difference between the increasing and decreasing cycle phases, while Dakar station data do show it, particularly for cycle 21. The percentage deviations of diurnal variations from solar-minimum conditions show more ionosphere during solar cycle 21 at both stations for all three of the other phases of the solar cycle. There is no significant variability of ionosphere during increasing and decreasing solar cycle phases at Ouagadougou station, but at Dakar station there is a significant variability of ionosphere during these two solar-cycle phases.

\section{Introduction}

Many ionosphere studies concern ionosphere parameter variability $[1,2]$ and do not include the African sector [3]. Moreover, some papers deal with the comparison between ionospheric data and the International Reference Ionosphere (IRI) [4-9]. On the other hand, many studies have investigated the solar-cycle variation and/or geomagnetic activity variation of the critical frequency of the F2 layer ([10-16]. It is important to know that few studies integrate African sector data, as noted by Bilitza et al. [3]), and take into account long series of data. In fact we have in the African sector the works which treat the variability of equatorial F2 density [17-23] in the equatorial ionization anomaly (EIA) trough, and in the Asian sector we have the works of Le Huy et al. [24] and Pham Thi Thu et al. [25], which concern the variability of the EIA trough for South East Asia and the southern EIA crest in the Asian sector.

The present study relies on the use of long series of data (three solar-cycles of foF2) which are obtained from the African sector and particularly from the Sub-Saharan African sector. It is well-known that in Africa, and especially in SubSaharan Africa, there is a lack of data. In the past only a few ionosonde stations operated (see Figure 1). In Figure 1, green points indicate the stations that operated in 1960 . We can see in Africa only four stations, with one station in West Africa (Dakar) and only two for the equatorial region (Dakar (lat: $14.8^{\circ} \mathrm{N}$; long: $342.6^{\circ} \mathrm{E}$ ) and Djibouti (lat: $11,5^{\circ} \mathrm{N}$; long: 


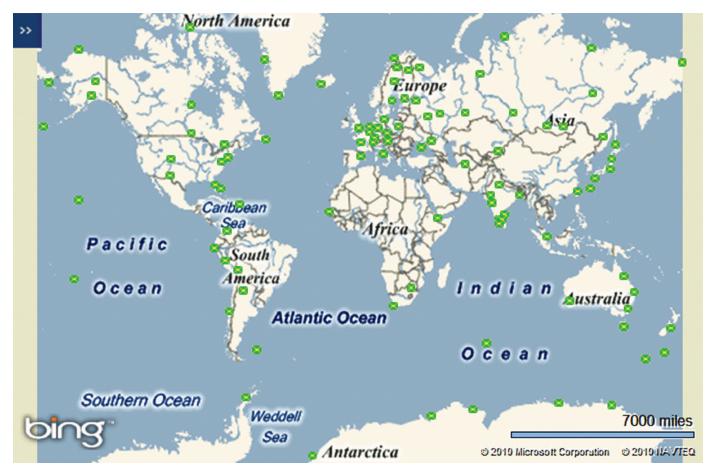

FIgURE 1: Ionosondes in operation in 1960.

$\left.42,8^{\circ} \mathrm{E}\right)$ ). After 1960 , we can add Ouagadougou station (lat: $12.4^{\circ} \mathrm{N}$; long: $358.5^{\circ} \mathrm{E}$ ), Tamanrasset station (lat: $22.80^{\circ} \mathrm{N}$; long: $354.47^{\circ} \mathrm{E}$ ), Ibadan station (lat: $7.43^{\circ} \mathrm{N}$; long: $356.10^{\circ} \mathrm{E}$ ), and recently Korhogo station (lat: $9.3^{\circ} \mathrm{N}$; long: $354.62^{\circ} \mathrm{E}$ ).

The objective of this paper is to determine (1) foF2 variability of two West African EIA stations with solar-cycle, season, and time of day and (2) to point out foF2 longitudinal variations. Comparison between data and models will be done in another study. It will be important before testing models to know well the variability of station data.

The structure of the paper is as follows. After the treatment of data and methodology in Sections 2 and 3, we present and discuss our results and end the paper by conclusion as Section 4 of the paper.

\section{Data Sets}

For this study, F2 layer critical frequency of (foF2) data obtained from two African EIA ionosonde stations: (1) Ouagadougou (lat: $12.4^{\circ} \mathrm{N}$; long: $358.5^{\circ} \mathrm{E}$; dip: +1.45 ) and (2) Dakar (lat: $14.8^{\circ} \mathrm{N}$; long: $342.6^{\circ} \mathrm{E}$; dip: +5.53 ). These data covered three solar-cycles (cycles 20, 21 and 22) and are provided by the Ecole Nationale de Télécommunication de Bretagne (ENST-Bretagne).

Sunspot number $\left(R_{z}\right)$ data obtained from the SPIDR web-site are also used in order to determine solar-cycle phases.

\section{Methodology}

Our database contains hourly foF 2 values which are going from June 1966 to February 1998 for Ouagadougou and from January 1971 to February 1997 for Dakar. For this work are considered years with $75 \%$ monthly available data (i.e., $9 / 12$ ratio of months per year). With this criterion, the available data go from 1971 to 1996 for Dakar and from 1965 to 1997 for Ouagadougou. For Ouagadougou, year 1986 must be excluded, for its available data are 5/12; but for the analysis of solar-cycle 22 data, weights have been used ( 1 for years with available number of months more than $75 \%, 0.75$ for years with available number of months between $75 \%$ and $50 \%$, and

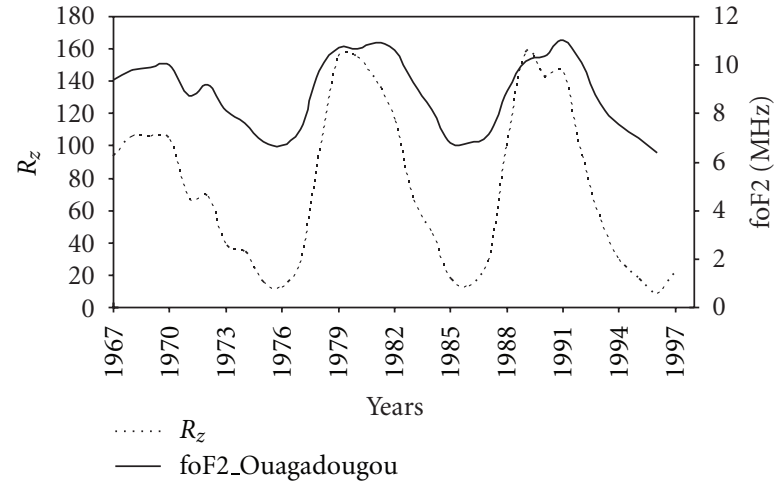

(a)

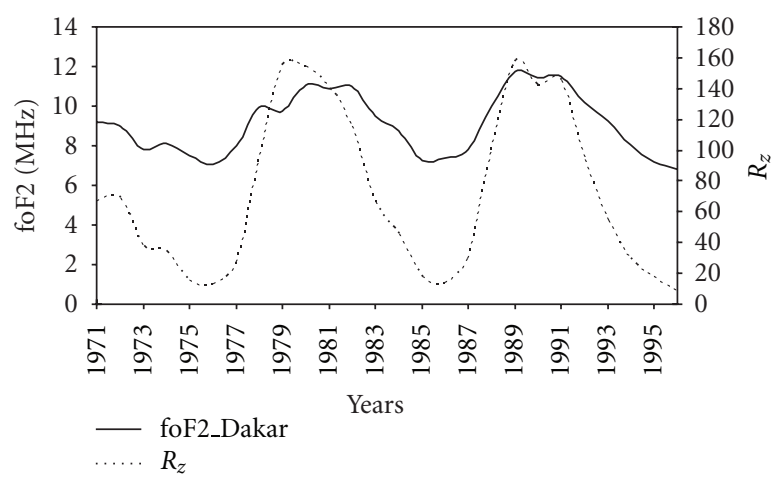

(b)

FIgure 2: Yearly variation of foF2 and $R_{z}$. (a) for Ouagadougou station and (b) for Dakar station.

0.5 when available number of months is less than 50\%) in order to integrate year 1986.

It is important to note that, for the retained years, all hourly data are available during a day, and for most of the retained years (more than 98\%) the number of months exceeds $75 \%$. Therefore, daily values are an arithmetic mean over all hours, monthly values are an arithmetic mean over all days, and annual values are an arithmetic mean over all months.

As foF2 is greatly influenced by solar ultraviolet radiation, foF2 variability with solar-cycle-phase must show solar ultraviolet radiation variation with respect to solar-cycle phase. Solar-cycle phases are determined by considering the following conditions (see [15, 26, 27]: (1) minimum phase: $R_{z}<20$, where $R_{z}$ is the yearly average Zürich sunspot number, (2) ascending phase: $20 \leq R_{z} \leq 100$ and $R_{z}$ greater than the previous year's value; (3) maximum phase: $R_{z}>100$ (for small solar-cycles (solar-cycles with sunspot number maximum $\left(R_{z} \max \right)$ less than 100$)$ the maximum phase is obtained by considering $R_{z}>0.8 * R_{z} \max$ ), and (4) descending phase: $100 \geq R_{z} \geq 20$ and $R_{z}$ less than the previous year's value. Table 3 gives the years of the different solar-cycle phases and their $R_{z}$ mean value.

foF2 variations are analysed by using (1) annual averaged data for solar-cycle variations, (2) monthly averaged data for seasonal variations, and (3) hourly averaged data for diurnal 
Ouagadougou

Monthly foF2 variability during solar minimum for all cycles

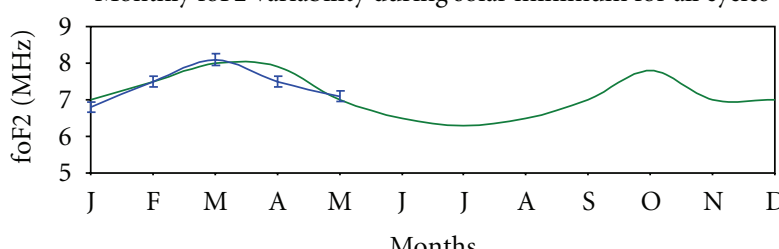

- foF 2 cycle 21

— foF 2 cycle 22

Monthly foF2 variability during increasing phase for all cycles

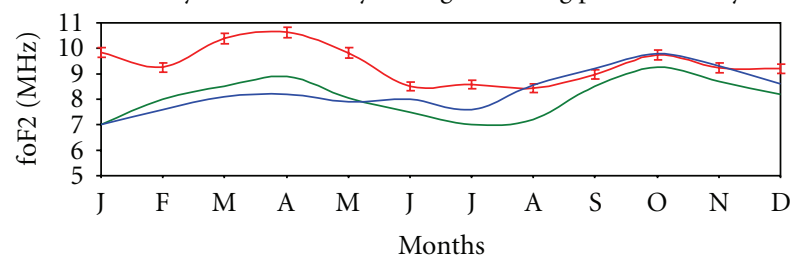

foF 2 cycle 20

- foF 2 cycle 21

— foF 2 cycle 22

Monthly foF2 variability during solar maximum for all cycles

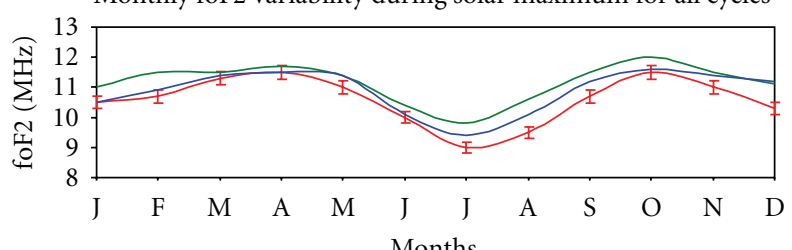

— foF 2 cycle 20

- foF 2 cycle 21

- foF 2 ctycle 22

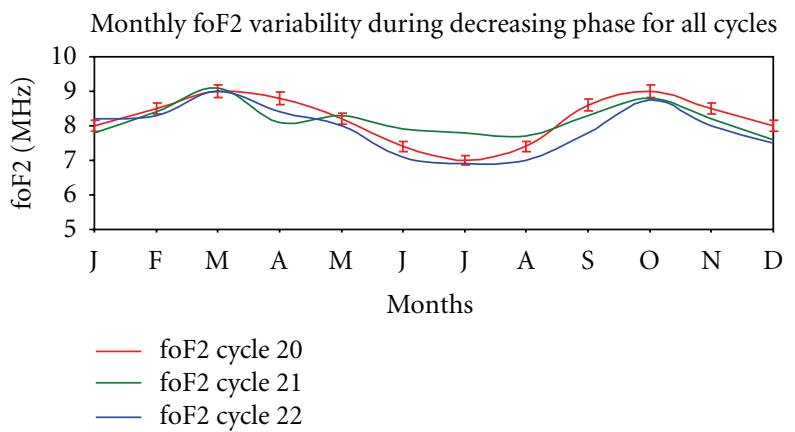

Dakar

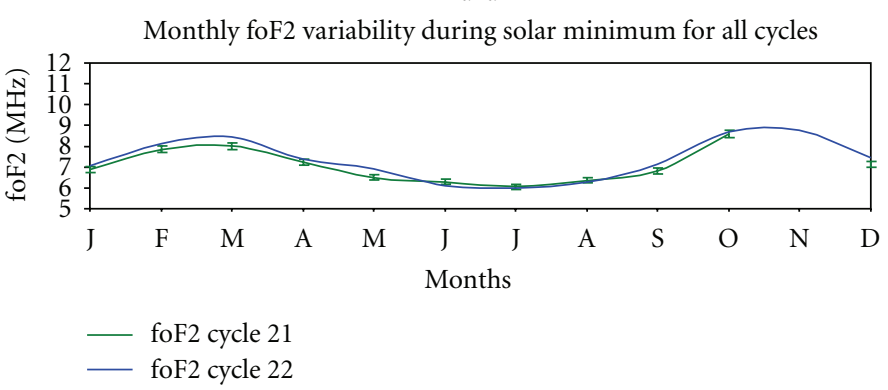

(a)

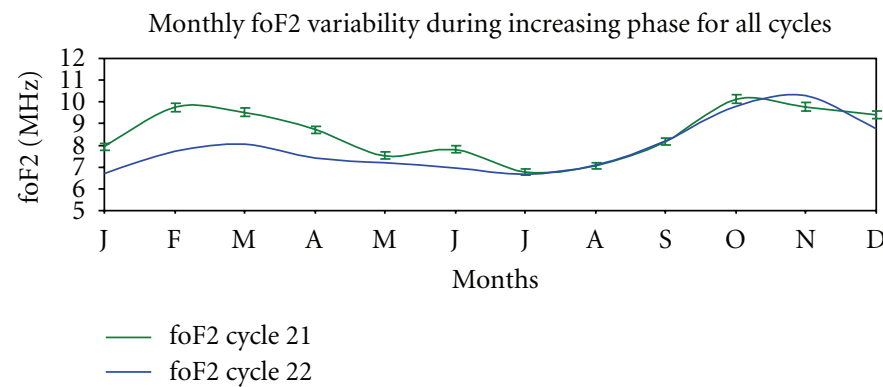

(b)

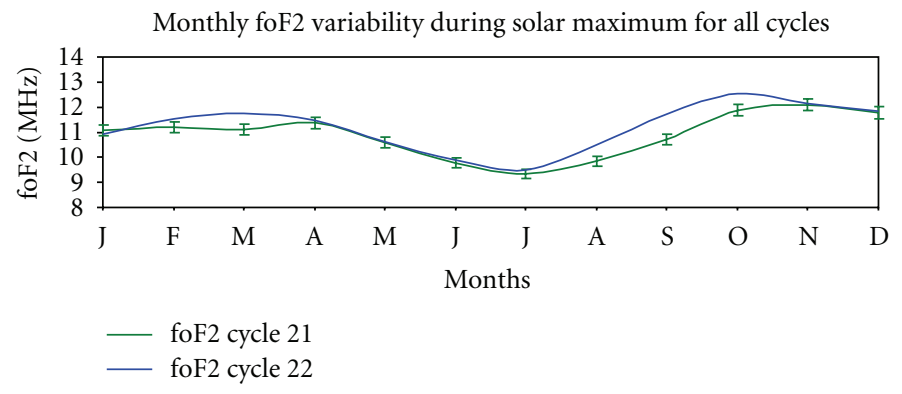

(c)

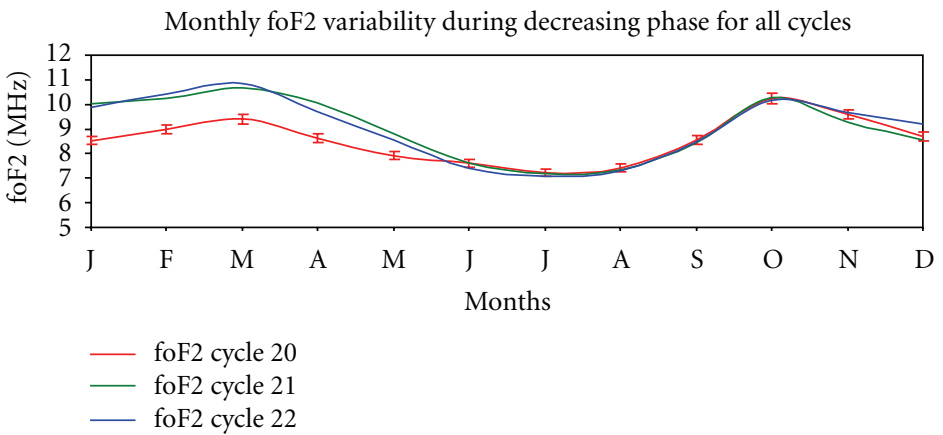

(d)

FIgure 3: Monthly variations of foF2 at the stations of Ouagadougou and Dakar for cycles 20, 21, and 22 (a) during solar minimum, (b) for increasing solar-activity, (c) during solar maximum; and (d) for decreasing solar-activity. 
TABLE 1: Correlation coefficients between foF2 and sunspot number $\left(R_{z}\right)$ from cycle 20 to cycle 22 .

\begin{tabular}{lcccc}
\hline Cycle & 20 & 21 & 22 & Location \\
\hline foF2 correlation & 0.977 & 0.973 & 0.948 & Ouagadougou \\
coefficient & 0.950 & 0.883 & 0.990 & Dakar \\
\hline
\end{tabular}

TABle 2: Predominance of March or September equinoctial peak for different solar-cycle phases.

\begin{tabular}{|c|c|c|c|c|c|c|c|}
\hline \multirow{3}{*}{$\begin{array}{l}\text { Solar cycle } \\
\text { phases }\end{array}$} & \multicolumn{6}{|c|}{ Solar cycles } & \multirow{3}{*}{ Nature of peak predominance } \\
\hline & \multicolumn{3}{|c|}{ Ouagadougou station } & \multicolumn{3}{|c|}{ Dakar station } & \\
\hline & 20 & 21 & 22 & 20 & 21 & 22 & \\
\hline \multirow{2}{*}{ Minimum } & $\mathbf{X}$ & $\mathrm{X}$ & $\mathrm{X}$ & & & & March/April \\
\hline & & & & $\mathbf{X}$ & $\mathbf{X}$ & $\mathbf{X}$ & September/October \\
\hline \multirow{2}{*}{ Increasing } & $\mathrm{X}$ & & & & & & March/April \\
\hline & & $\mathrm{X}$ & $\mathrm{X}$ & $\mathbf{X}$ & $\mathbf{X}$ & $\mathbf{X}$ & September/October \\
\hline \multirow{2}{*}{ Maximum } & & & & & & & March/April \\
\hline & $\mathbf{X}$ & $\mathbf{X}$ & $\mathbf{X}$ & $\mathbf{X}$ & $\mathbf{X}$ & $\mathbf{X}$ & September/October \\
\hline \multirow{2}{*}{ Decreasing } & $\mathrm{X}$ & $\mathrm{X}$ & $\mathrm{X}$ & & $\mathrm{X}$ & $\mathrm{X}$ & March/April \\
\hline & & & & $\mathbf{X}$ & & & September/October \\
\hline
\end{tabular}

variations. These analyses are made by taking into account solar-cycle phases.

As the solar-cycle 20 maximum $\left(R_{z}=105.9\right)$ is smaller than the maxima of cycles 21 and 22 (their maxima are comparable: 155.4 and 157.6, resp.; see Figure 2) we put error bars $(\sigma=\sqrt{\Delta}$, where $\Delta$ is the variance defined by $(1 / N) \sum_{i=1}^{N}\left(x_{i}-\bar{x}\right)^{2}$ with $\bar{x}$ mean value) of solar-cycle 20 data in Figure 3 in order to have a reference for the significance of solar-cycle differences. In case of lack of cycle 20 data, error bars of the solar-cycle 21 data are shown. Error bars of the solar minimum data are also shown in Figure 4 in order to have a reference for the significance of differences from the other solar-cycle phases.

For analyzing foF2 variability, we will use qualitative analysis based on examination of data plots (error bars will help us for this analysis) and quantitative analysis based on percentage deviation, expressed as $\sigma_{\text {rel }}=\left(\left(x_{i}^{0}-x_{i}^{m}\right) / x_{i}^{m}\right) \times$ 100 , where $x_{i}^{0}$ and $x_{i}^{m}$ are either (1) the monthly averaged foF2 data during the solar-cycle 20 (in case of lack of solarcycle 20 data it expresses solar-cycle 21 data) and foF 2 data during the other solar-cycles (in case of lack of solar-cycle 20 data it will be solar-cycle 22 data), respectively, for seasonal studies shown in Figure 3 or (2) solar minimum phase foF2 data and foF2 data of the other solar-cycle phase, respectively, for diurnal studies shown in Figure 4. For studying seasonal variation of foF2, we quantify the difference between each solar-cycle of foF2 data and its variability. As $\sigma_{\text {rel }}<0$ shows higher foF 2 and $\sigma_{\text {rel }}>0$ lower foF 2 than the reference less, the diurnal percentage deviation permits to study the variability of ionosphere.

\section{Results and Discussions}

4.1. Qualitative Analysis. Figure 2 shows the plot of $R_{z}$ and foF2 for Ouagadougou station (panel a) and Dakar station (panel b) for available data of the three solar-cycles. It can be seen good correlation between $R_{z}$ and foF 2 for these two stations.

Table 1 shows the correlation coefficient between foF2 and $R_{z}$ throughout the three solar-cycles $(20,21$, and 22) for the two stations (Dakar and Ouagadougou). It can be seen for both stations the decrease of correlation coefficient from cycle 20 to cycle 21 . The correlation coefficient decreases from cycle 21 to cycle 22 for Ouagadougou station and increases for Dakar station. Throughout the three solarcycles, the best correlation is seen at Dakar station (0.990) even if the correlation is better at Ouagadougou station than Dakar station for cycles 20 and 21.

Figure 3 presents monthly mean variations of foF 2 for the three solar-cycles during the four solar-cycle phases. The left panels concern Ouagadougou data and the right panels Dakar data. Panel (a) corresponds to solar-cycle minimum phase, panel (b) solar-cycle increasing phase, panel (c) solarcycle maximum phase and panel (d) solar-cycle decreasing phase.

The red lines represent monthly mean variation of cycle 20 data, green lines those of cycle 21 and blue lines cycle 22 data.

The left panel (a) shows a lack of data during the minimum phase of solar-cycle 20 (absence of red line) for Ouagadougou, which operated since 1966 (with data available since 1967). The lack of data is also observed in the right panels (a), (b), and (c) (absence of red lines in these panels), because available data at Dakar station begins in 1971.

Figure 3 highlights the well-known seasonal variation of foF2 with two asymmetric peaks (error bars help us to see this asymmetry) at the equinoxes except at Ouagadougou during the decreasing phase and little bit during the maximum phase. From one cycle to another or from one phase to another, the predominance of the equinoctial peaks varies. 
TABLE 3: Years of the different solar-cycle phases and their $R_{z}$ mean value.

\begin{tabular}{|c|c|c|c|c|c|}
\hline \multirow{2}{*}{ Solar-cycles } & \multicolumn{5}{|c|}{ Solar-cycle phases } \\
\hline & Minimum & Increasing & Maximum & Decreasing & Years and $R_{z}$ mean \\
\hline \multirow{2}{*}{20} & $1964-1965$ & $1966-1967$ & $1968-1970$ & $1971-1974$ & Years \\
\hline & 12.6 & 70.4 & 105.3 & 52 & $R_{z}$ mean \\
\hline \multirow{2}{*}{21} & $1975-1976$ & $1977-1978$ & $1979-1982$ & $1983-1984$ & Years \\
\hline & 14.1 & 60 & 141.6 & 56.3 & $R_{z}$ mean \\
\hline \multirow{2}{*}{22} & 1985-1986 & 1987 & 1988-1989 & 1992-1994 & Years \\
\hline & 15.7 & 29.4 & 136.5 & 59.6 & $R_{z}$ mean \\
\hline
\end{tabular}

Ouagadougou

Diurnal foF2 variability during cycle 21 for all phases

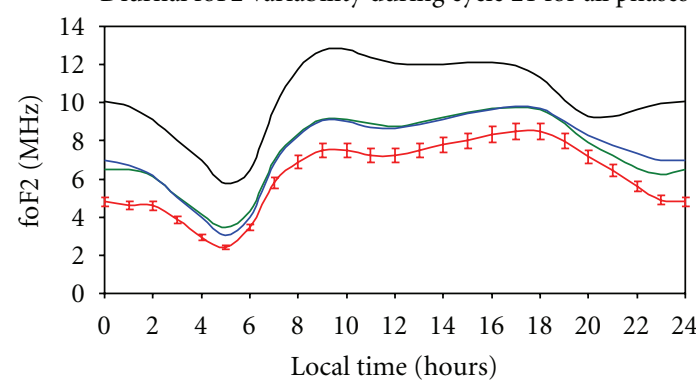

$\begin{array}{ll}\text { foF2 minimum } & - \text { foF2 maximum } \\ \text { foF2 increasing } & \text { foF2 decreasing }\end{array}$

Diurnal foF2 variability during cycle 22 for all phases

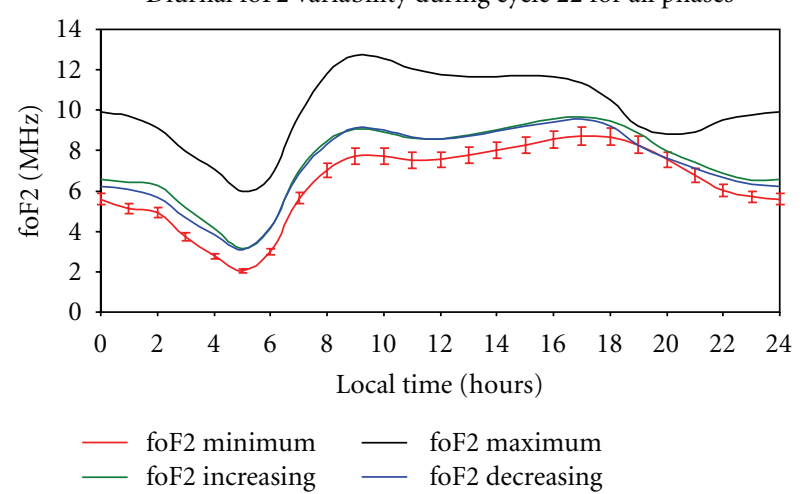

(a)
Dakar

Diurnal foF2 variability during cycle 21 for all phases
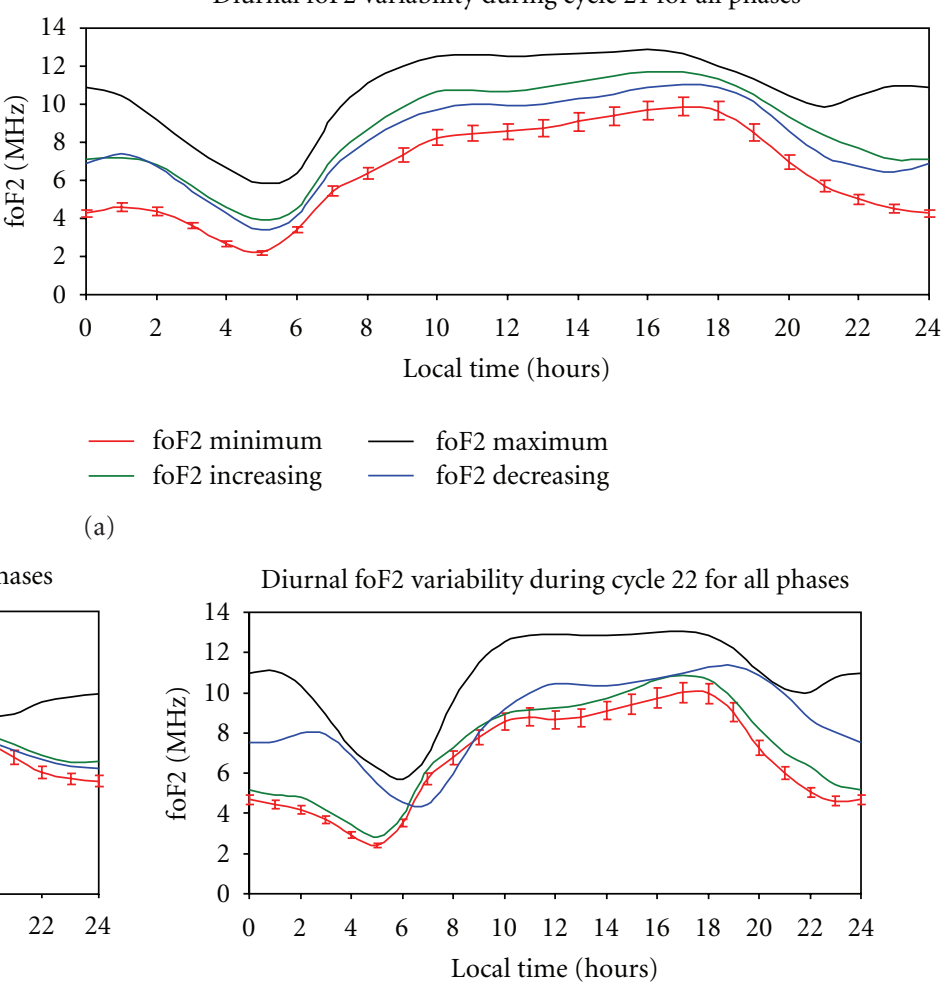

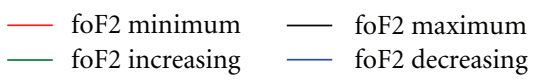

(b)

Figure 4: Diurnal variation of foF2 at Ouagadougou station (left panels) and at Dakar station (right panels). Panel (a) concerns solar-cycle 31 and panel (b) solar-cycle 22 .

During June solstice, at Dakar for all solar-cycles, the density of ionization is the same. Whatever the station, the maximum of ionization appears always in October. The other maximums appear sometimes in March and sometimes in April. During solar-cycle maximum phase, foF2 profiles are regular and the density of ionization grows from cycle 20 to cycle 21.

Table 2 shows the peak predominance. It can be concluded that (1) during the minimum phase each station exhibits the same peak predominance (March/April for Ouagadougou station and September/October for Dakar station); (2) during the maximum phase, only September/October predominance is observed at both stations; (3) during the increasing phase we observe September/October predominance at both stations except for cycle 20 for Ouagadougou; (4) during the decreasing phase March/April predominance is observed for both stations except for solarcycle 20 at Dakar. These observations (different monthly locations of peak predominance throughout the solar-cycle phases) suggest the necessity to analyse the variability of the ionosphere by taking into account each solar phase and not to consider only minimum and high solar-activity. The 
Ouagadougou

Deviation for minimum phase (\%)

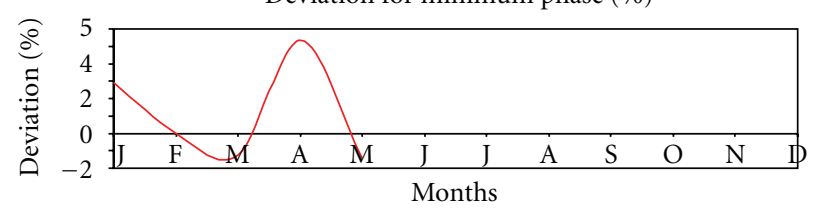

- Cycles 22-21 (\%)

Deviation for increasing phase (\%)

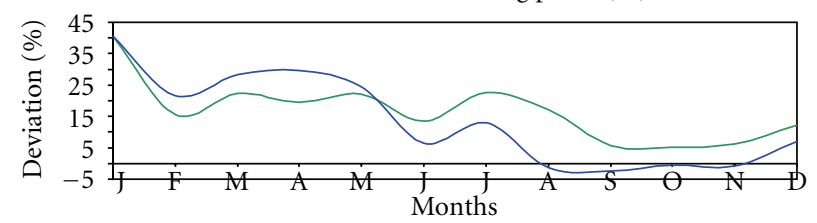

Cycles 21-20 (\%)

- Cycles 22-20 (\%)

Deviation for maximum phase (\%)

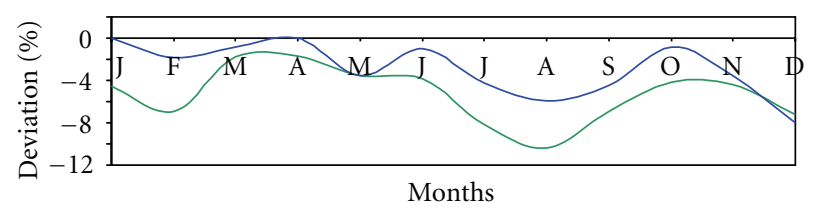

- Cycles 21-20 (\%)

- Cycles 22-20 (\%)

Deviation for decreasing phase (\%)

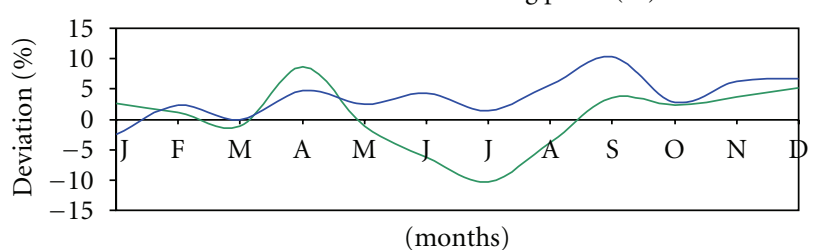

- Cycles 21-20 (\%)

- Cycles 22-20 (\%)

(a)

(b)

(c)

Dakar

Deviation for minimum phase (\%)

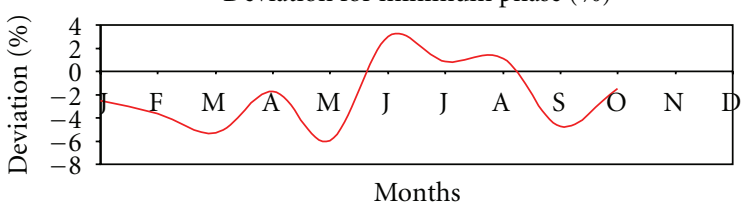

— Cycles 22-21 (\%)

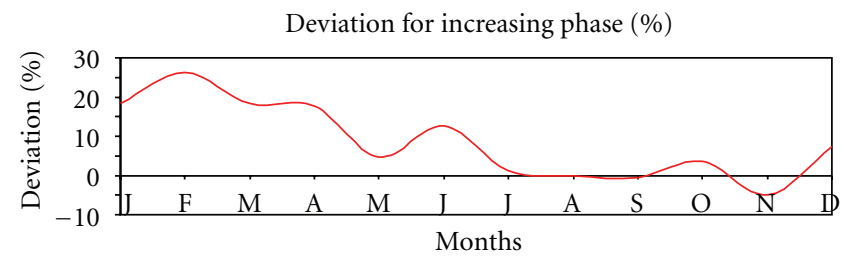

— Cycles 22-21 (\%)
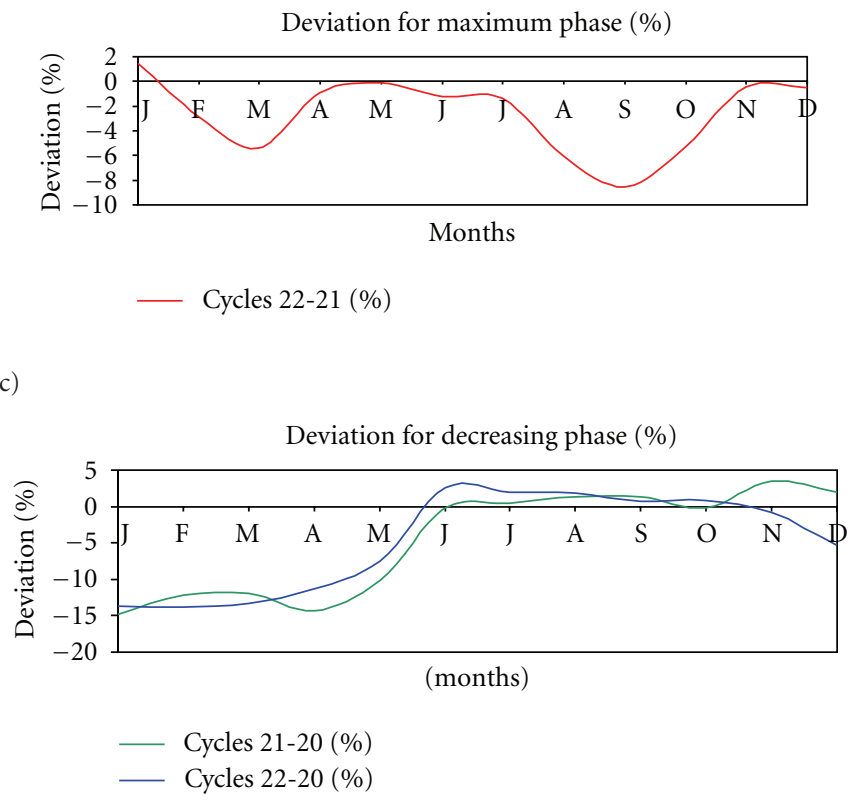

(d)

Figure 5: Percentage deviations of monthly average data from one solar-cycle to another with respect to month and solar-cycle phase. The left panels are for Ouagadougou and the right panels are for Dakar.

difference of predominant peak locations between the two stations may be due to longitudinal variation of the F2 layer critical frequency.

Figure 4 gives local time variations of foF 2 for cycles 21 and 22 . We do not consider here cycle 20 because only minimum and decreasing phase data are available. On the left we have Ouagadougou data and on the right Dakar data. Panels (a) and (b) show the local time variation of foF2 during cycles 21 and 22, respectively. Red lines correspond to the minimum phase, green lines the increasing phase, blue lines the decreasing phase, and black lines the maximum phase. foF2 during solar maximum phase of both solar-cycles 21 and 22 presents a secondary maximum during night time, which expresses the effect of the prereversal electric field in foF2 profiles. In fact, eastward daytime electric field at equatorial ionosphere ( $\mathrm{E}$ and $\mathrm{F}$ regions) exhibits a significant increase just it reverses to its night time westward direction $[28,29]$. The theoretical models of the low-latitude fields suggest that this enhancement is either caused mainly or entirely by $\mathrm{F}$ region winds (e.g., [30-33]) or produced solely by $\mathrm{E}$ region tidal winds (e.g., $[34,35])$. The prereversal enhancement of the zonal electric field in the equatorial 


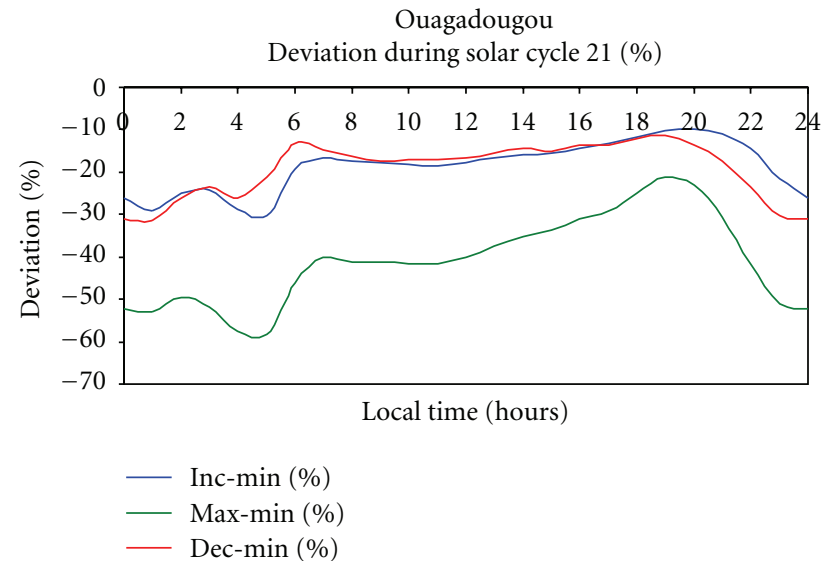

(a)

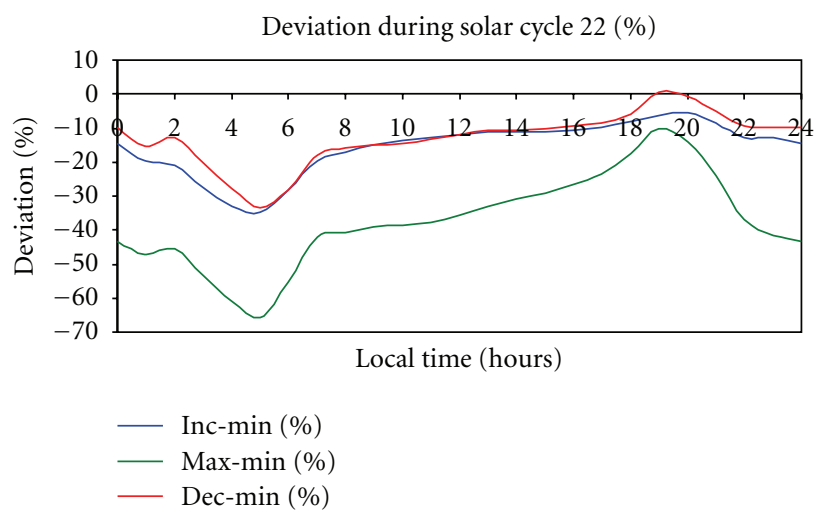

Dakar
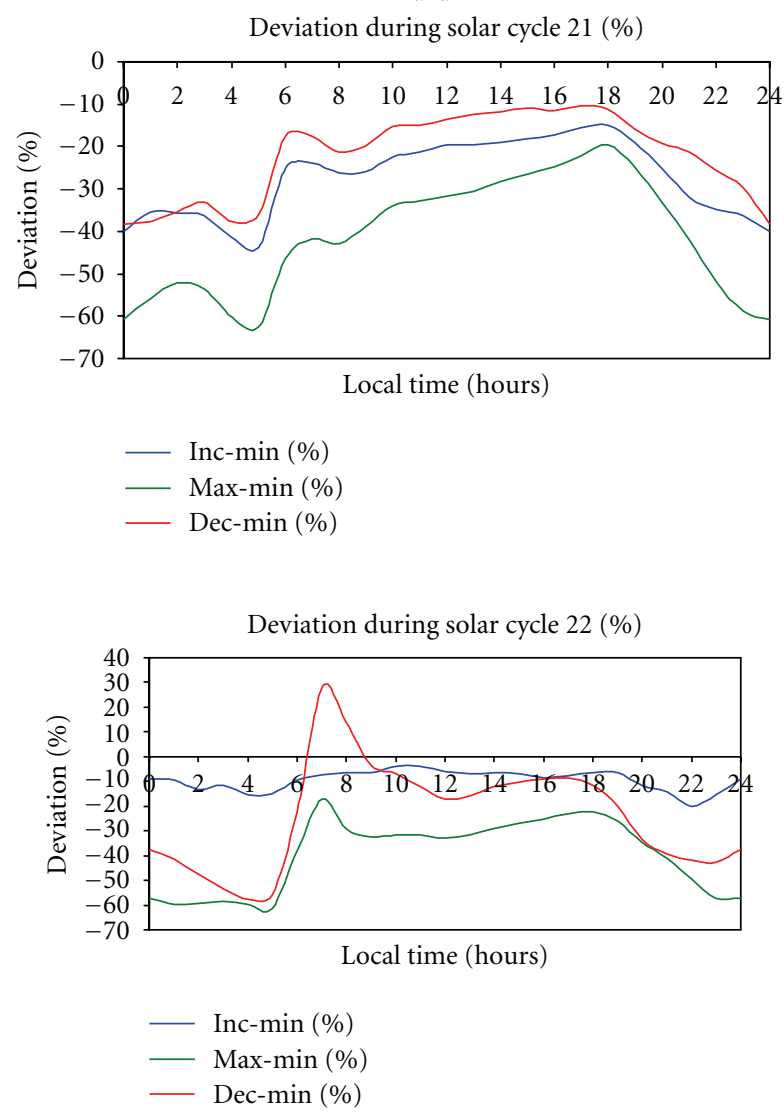

(b)

FIGURE 6: Percentage deviations (with sign reversed) of diurnal variations with respect to solar minimum conditions for three solar-cycle phases: increasing (blue), maximum (green), and decreasing (red).

ionosphere is well-known [33] and depends on season, level of magnetic activity, and phase of the solar-cycle $[33,36]$. On a given day it might be absent, but it is a persistent feature of averaged data [33]. Fejer et al. [36] note that the occurrence of a sharp increase of the upward velocity in the dusk sector just before it reverses to its downward direction is the main characteristic of the equatorial $\mathrm{F}$ region vertical drift. They also pointed out that the evening upward velocity enhancement is responsible for the rapid rise of the equatorial $\mathrm{F}$ layer after sunset.

The analysis of Figure 4 points out for Ouagadougou station (left panels) the similarity of the increasing and decreasing phases for both cycles. The foF 2 increases from the minimum phase to the maximum phase. The local time variation of foF 2 during the all solar-activity phases present a noon bite out, with late-afternoon/evening maxima for all lines except for the maximum phase, where there is a secondary minimum in the early evening. All solar-activity phases foF2 start to increase before sunrise (before $0600 \mathrm{LT}$ ) and there is no difference of foF2 between increasing and decreasing phases for both solar-cycles.

Table 3 shows that for solar-cycle 21 solar-activity during increasing phase is higher than during decreasing phase and that it is the reverse for solar-cycle 22. Normally, foF2 of both stations and for both solar-cycles must vary with respect to solar-activity. Therefore the same local time variation of Ouagadougou foF2 data for both solar-cycles during solar increasing and decreasing phases must be explained by the bias of data classification with respect to the solar-cycle activity.

At Dakar (right panels) the lines for the increasing and decreasing phases are similar through a whole day for solarcycle 21 but only at daytime for cycle 22 . foF 2 at this station also increases from solar minimum to solar maximum. It can be mentioned from this figure that an enhancement of foF2 occurs around midnight during solar maximum and that the foF 2 enhancement can be seen before sunrise during solar decreasing phase. All solar-activity phases foF 2 increase before sunrise (before $0600 \mathrm{LT}$ ) except during solar-activity maximum and decreasing phases of solar-cycle 22 where foF2 increases after sunrise (between $0600 \mathrm{LT}$ and $0800 \mathrm{LT}$ ). The right panel (b) of Figure 4 shows that solar-activity increasing phase foF 2 is higher than that of decreasing phase during both solar-cycles except between 0600 LT and 0900 LT during solar-cycle 22 where it is the reverse. By taking into account the results of Table 3 , the local time variation of foF2 
between 0600 LT and 0900 LT during solar-activity increasing and decreasing phases with no respect to solar-activity must be due to the difference between their foF2 data daytime increasing times.

The Ouagadougou data (left panels) show no difference of foF2 between the solar-activity decreasing and increasing phases. At Dakar (right panels); on the other hand, difference of foF 2 between the increasing and decreasing phases is seen. The difference is larger during cycle 21 than that of cycle 22. For solar-cycle 22 , foF 2 is higher during the decreasing phase than during the increasing phase. This result has been pointed out by Özgüç et al. [12]. It can be also noted that at Dakar station, during solar-cycle 22 at daytime, foF2 does not change from minimum phase to increasing phase (see the error bars shown on the red curve).

The results of Figure 4 prevent us from treating together the variability of the foF2 for the increasing and decreasing phases as done by Bilitza et al. [3] for moderate solar-activity, for it depends on the station. This point of view has been considered in the work of Özgüç et al. [12] and Ataç et al. [13].

The difference between the Dakar and Ouagadougou electron densities shows the necessity to study separately the data from these kinds of stations, as foF2 shows longitudinal effects.

4.2. Quantitative Analysis. Figures 5 and 6 concern the evolution of the percentage deviation. The right panels concern Ouagadougou and the left panels Dakar.

In Figure 5 the green curves express the percentage deviation between the values of foF 2 for solar-cycle 21 and these for solar-cycle 20. Blue curves give the percentage deviation between foF 2 values of solar-cycle 22 and foF 2 values of solar-cycle 20. The red curves express the same thing, but for solar-cycles 21 and 22.

Figure 5 shows for a given solar-cycle phase the same variability of percentage deviation graphs. Percentage deviation graphs decrease (1) from January to March/April during minimum phase, (2) from January to July/August during increasing phase, and (3) from January to August/September during maximum phase. The similar variation of the percentage deviation at both stations for the minimum, increasing, and maximum phases may be expressed the non longitudinal dependence of monthly solar ultraviolet radiation variability.

The phase-to-phase variability of the percentage variations shows the necessity to take into account the different solar-cycle phases in the study of ionosphere. The different variability of the percentage deviation values between the March and September equinox periods is related to the equinoctial asymmetry previously noted in the qualitative analysis. The qualitative analysis shows the phase-to-phase variability of foF2.

Figure 6 shows negative values of percentage deviation. We can assert that there is higher electron density during increasing, maximum, and decreasing solar-cycle phases than solar minimum phase. The quantity of foF2 is the highest during solar maximum phase at both stations and for both solar-cycles.

In Figure 6(a), the quantity of foF2 decreases from maximum phase to increasing phase for all stations and then decreases from increasing phase to decreasing phase at Dakar station; at Ouagadougou station this quantity is fairly constant during daytime.

In Figure 6(b), we observe the same phase-to-phase variation of foF2 at Ouagadougou station while at Dakar station the quantity of foF2 during the decreasing phase is higher than during the increasing phase.

In Figure 6, except during decreasing phase of solarcycle 22 at Dakar station (blue curve in right panel (b)), all curves show double peaks: morning peak 0600 LT-0800 LT and afternoon or evening peak 1600 LT-2000 LT.

\section{Conclusion}

This study shows the correlation between foF2 and $R_{z}$ for Ouagadougou and Dakar data. The correlation coefficient varies from one solar-cycle to another. The best correlation is observed at Dakar during solar-cycle 22. Seasonal variations of foF2 present asymmetric equinoctial peaks which vary among the different solar-cycle phases. The foF 2 shows the phase-to-phase variability of the solar-activity due to solar ultraviolet radiation variability. At Ouagadougou station, foF2 during the solar-activity increasing phase is almost identical to that during the decreasing phases while at Dakar station foF2 is higher during the decreasing phase than during the increasing phase. It can be concluded that it is necessary to treat separately the variability of the ionosphere according to each type of solar-cycle phase.

\section{Acknowledgments}

Authors thank the Ecole Nationale de Télécomunication de Bretagne (ENST-Bretagne) and, SPIDR webmaster for providing data. Authors also thank Dr. Rolland Fleury and Dr. Patrick Lassudrie Duchesne from the ENST-Bretagne for their collaboration and Dr. Arthur Richmond from $\mathrm{HAO}$ at NCAR for his proofreading and advices. Thanks to International Journal of Geophysics editor and reviewers for their kindly remarks, suggestions, and propositions which allow them to improve the paper.

\section{References}

[1] H. Risbeth and M. Mendillo, "Patterns of F2 layer variability," Journal of Atmospheric and Solar-Terrestrial Physics, vol. 63, pp. 1661-1680, 2001.

[2] D. N. Fotiadis, G. M. Baziakos, and S. S. Kouris, "On the global behaviour of the day-to-day MUF variation," Advances in Space Research, vol. 33, no. 6, pp. 893-901, 2004.

[3] D. Bilitza, O. K. Obrou, J. O. Adeniyi, and O. Oladipo, "Variability of foF2 in the equatorial ionosphere," Advances in Space Research, vol. 34, no. 9, pp. 1901-1906, 2004.

[4] J. O. Adeniyi and I. A. Adimula, "Comparing the F2-layer model of IRI with observations at Ibadan," Advances in Space Research, vol. 15, no. 2, pp. 141-144, 1995.

[5] J. O. Adeniyi and S. M. Radicella, "Diurnal variation of ionospheric profile parameters $\mathrm{B} 0$ and $\mathrm{B} 1$ for an equatorial 
station at low solar activity," Journal of Atmospheric and SolarTerrestrial Physics, vol. 60, no. 3, pp. 381-385, 1998.

[6] J. O. Adeniyi and S. M. Radicella, "Variation of bottomside profile parameters B0 and B1 at high solar activity for an equatorial station," Journal of Atmospheric and SolarTerrestrial Physics, vol. 60, no. 11, pp. 1123-1127, 1998.

[7] J. R. de Souza, G. J. Batley, M. A. Abdu, and I. S. Batista, "Comparison of low latitude F region peak densities, heights and equatorial ExB drift from IRI with obervational data and the Sheffield University plasmasphere ionosphere model," Advances in Space Research, vol. 18, pp. 41-44, 1996.

[8] I. S. Batista and M. A. Abdu, "Ionospheric variability at Brazilian low and equatorial latitudes: Comparison between observations and IRI model," Advances in Space Research, vol. 34, no. 9, pp. 1894-1900, 2004.

[9] K. O. Obrou, Ionosphère équatoriale: contribution à l'amélioration du modèle International Reference Ionosphere (IRI), Thèse de Doctorat d'état es Sciences Physiques, UFR SSMT. Université de Cocody, 2008.

[10] P. A. Bradley, "Indices of ionospheric response to solar-cycle epoch," Advances in Space Research, vol. 13, no. 3, pp. 25-28, 1993.

[11] S. S. Kouris, P. A. Bradley, and I. K. Nissopoulos, "The relationships of foF2 and M(3000)F2 versus $\mathrm{R}_{12}$," in Proceedings of the COST 238/PRIME/ Workshop, pp. 155-167, Eindhoven, The Netherlands, 1994.

[12] A. Özgüç, T. Ataç, and R. Pektaş, "Examination of the solar cycle variation of foF2 for cycles 22 and 23," Journal of Atmospheric and Solar-Terrestrial Physics, vol. 70, no. 2-4, pp. 268-276, 2008.

[13] T. Ataç, A. Özgüç, and R. Pektaş, "The variability of foF2 in different phases of solar cycle 23," Journal of Atmospheric and Solar-Terrestrial Physics, vol. 71, no. 5, pp. 583-588, 2009.

[14] J. Lei, J. P. Thayer, J. M. Forbes et al., "Ionosphere response to solar wind high-speed streams," Geophysical Research Letters, vol. 35, no. 19, Article ID L19105, 2008.

[15] F. Ouattara, C. Amory-Mazaudier, R. Fleury, P. Lassudrie Duchesne, P. Vila, and M. Petitdidier, "West African equatorial ionospheric parameters climatology based on ouagadougou ionosonde station data from june 1966 to february 1998," Annales Geophysicae, vol. 27, no. 6, pp. 2503-2514, 2009.

[16] D. H. Zhang, X. H. Mo, L. Cai et al., "Impact factor for the ionospheric total electron content response to solar flare irradiation," Journal of Geophysical Research A, vol. 116, no. 4, Article ID A04311, 2011.

[17] E. Sambou, P. M. Vila, and A. T. Kobea, "Non-trough foF2 enhancements at near-equatorial dip latitudes," Annales Geophysicae, vol. 16, no. 6, pp. 711-720, 1998.

[18] O. K. Obrou, D. Bilitza, J. O. Adeniyi, and S. M. Radicella, "Equatorial F2-layer peak height and correlation with vertical ion drift and M(3000)F2," Advances in Space Research, vol. 31, no. 3, pp. 513-520, 2003.

[19] D. Bilitza, O. K. Obrou, J. O. Adeniyi, and O. Oladipo, "Variability of foF2 in the equatorial ionosphere," Advances in Space Research, vol. 34, no. 9, pp. 1901-1906, 2004.

[20] O. K. Obrou, J. O. Adeniyi, A. T. Kobea, and B. Moukassa, "Electron density profile parameters B0 and B1 response during a magnetic disturbance at equatorial latitude," Journal of Atmospheric and Solar-Terrestrial Physics, vol. 67, no. 5, pp. 515-519, 2005.

[21] O. A. Oladipo, J. O. Adeniyi, S. M. Radicella, and O. K. Obrou, "Variability of equatorial ionospheric electron density at fixed heights below the F2 peak," Journal of Atmospheric and SolarTerrestrial Physics, vol. 70, no. 7, pp. 1056-1065, 2008.
[22] F. Ouattara and J. L. Zerbo, "Ouagadougou station F2 layer parameters yearly and seasonal variations during severe geomagnetic storms generated by CMEs and fluctuating wind streams," International Journal of Physical Sciences, vol. 6, no. 20, pp. 4854-4860, 2011.

[23] F. Ouattara and C. Amory Mazaudier, "Statistical study of the diurnal variation of the Equatorial F layer at Ouagadougou from 1966 to 1998," submitted to special issue of the Journal of Space Weather and Space Climate.

[24] M. Le Huy, C. T. Nguyen, T. L. Tran et al., "The effect of the geomagnetic storm on the ionospheric total electron content in the Southeast Asian equatorial ionization anomaly region observed by the GPS data," Journal of Sciences of the Earth, vol. 29, no. 2, pp. 104-112, 2007.

[25] H. Pham Thi Thu, C. Amory-Mazaudier, and M. Le Huy, "Time variations of the ionosphere at the northern tropical crest of ionization at Phu Thuy, Vietnam," Annales Geophysicae, vol. 29, no. 1, pp. 197-207, 2011.

[26] F. Ouattara, "Solar magnetic fields components: phases, profiles and their relationships," Journal of Science, vol. 9, no. 2, pp. 9-16, 2009.

[27] J. L. Zerbo, F. Ouattara, C. Zoundi, and A. Gyébré, "Solar cycle 23 and geomagnetic activity since 1868," La Revue CAMES: La Série A, vol. 12, no. 2, pp. 255-262, 2011.

[28] B. G. Fejer, D. T. Farley, R. F. Woodman, and C. Calderon, "Dependence of equatorial F region vertical drifts on season and solar cycle," Journal of Geophysical Research, vol. 84, no. 10, pp. 5792-5796, 1979.

[29] B. G. Fejer, "The equatorial ionospheric electric fields. A review," Journal of Atmospheric and Terrestrial Physics, vol. 43, no. 5-6, pp. 377-386, 1981.

[30] H. Rishbeth, "The F-layer dynamo," Planetary and Space Science, vol. 19, no. 2, pp. 263-267, 1971.

[31] R. A. Heelis, P. C. Kendall, R. J. Moffeit, D. W. Windle, and H. Rishbeth, "Electrical coupling of the E- and F-regions and its effect on F-region drifts and winds," Planetary and Space Science, vol. 22, no. 5, pp. 743-756, 1974.

[32] N. Matuura, "Electric fields deduced from the thermosphere model," Journal of Geophysical Research, vol. 79, p. 4679, 1974.

[33] D. T. Farley, E. Bonell, B. G. Fejer, and M. F. Larsen, "The prereversal enhancement of the zonal electric field in the equatorial ionosphere," Journal of Geophysical Research, vol. 91, no. 13, pp. 723-728, 1986.

[34] E. K. Walton and S. A. Bowhill, "Seasonal variations in the low latitude dynamo current system near sunspot maximum," Journal of Atmospheric and Terrestrial Physics, vol. 41, no. 9, pp. 937-949, 1979.

[35] R. J. Stening, "A two-layer ionospheric dynamo calculation," Journal of Geophysical Research, vol. 86, p. 3543, 1981.

[36] B. G. Fejer, E. R. de Paula, S. A. Gonzalez, and R. F. Woodman, "Average vertical and zonal F region plasma drifts over Jicamarca," Journal of Geophysical Research, vol. 96, no. 8, pp. 901-906, 1991. 

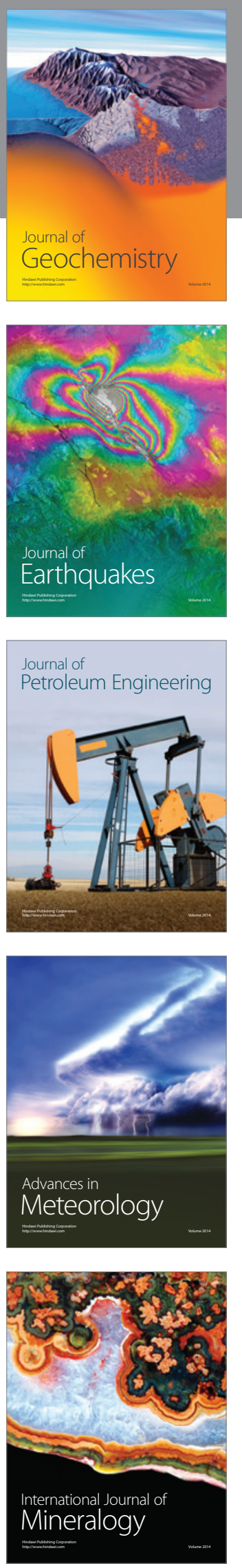
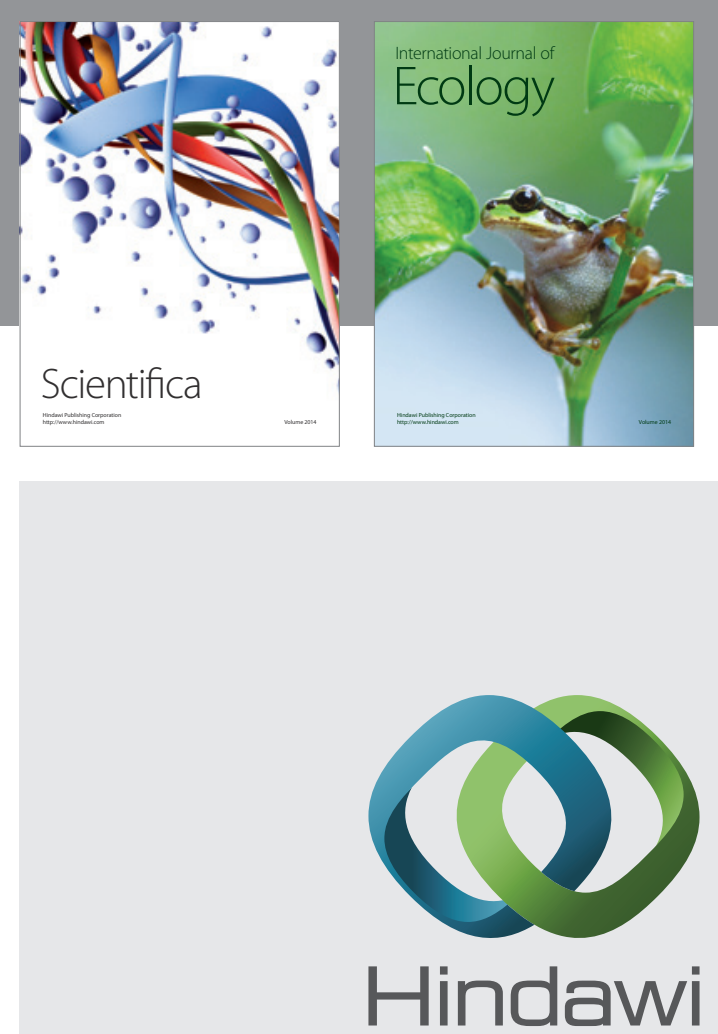

Submit your manuscripts at http://www.hindawi.com
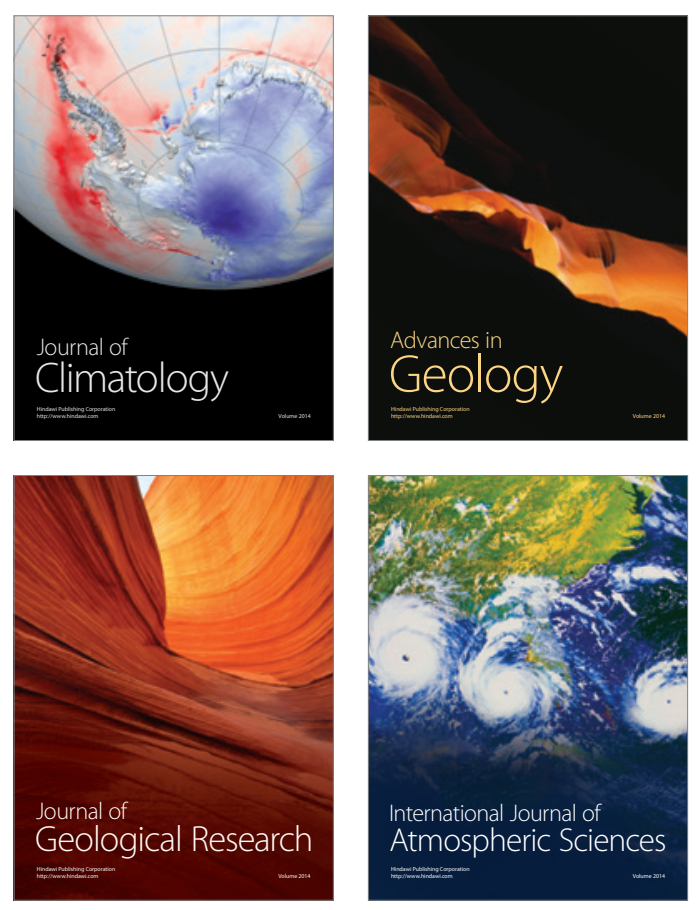
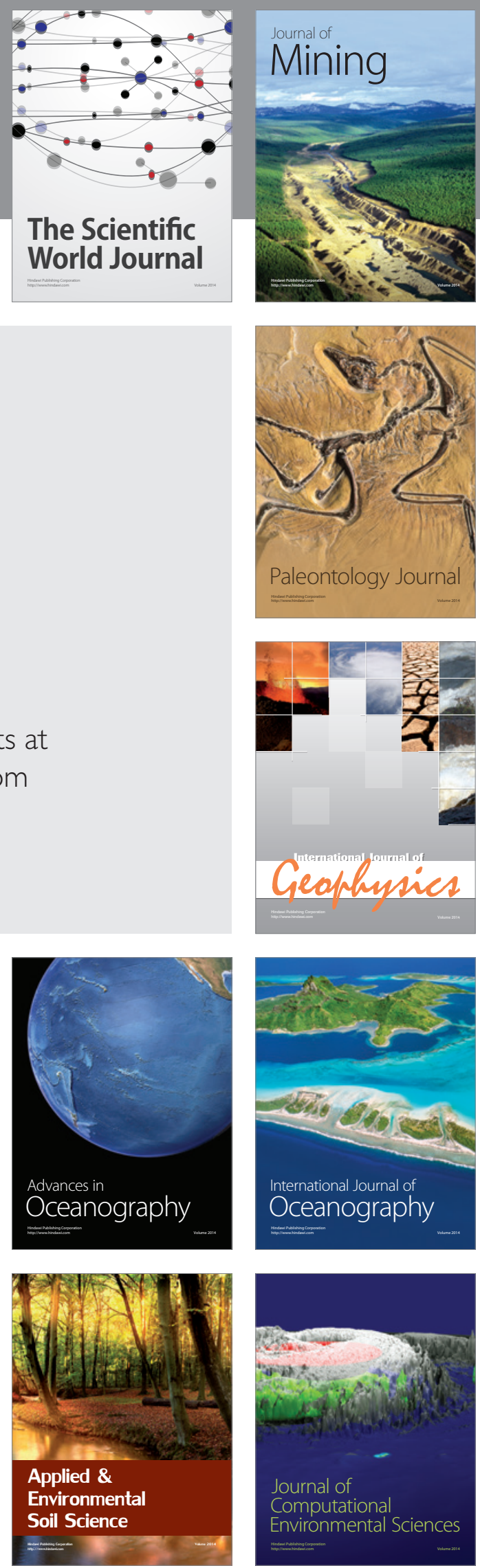